\title{
Penalizing hospitals for bad care
}

$\mathrm{U}$ nlike restaurant owners or retail managers, people who run hospitals theoretically don't want repeat customers. Yet they often get them, particularly poor-performing hospitals with high readmission rates. And because a hospital gets paid for performing procedures, in one form or another, it could be argued that it is good for business when a patient needs additional treatment because of a negative outcome, even if the hospital were responsible for that adverse event.

"This perverse financial incentive represents a fundamental flaw in the existing payment system design," states a recent paper that suggests hospitals should receive payments according to outcomes (Jt Comm J Qual Patient Saf 2011;37:184-92). "However, this incentive can be eliminated if hospital payment rates are adjusted to reflect the outcomes that a hospital actually achieves."

This model of payment is referred to as "pay for outcomes," or P4O for short. Proponents say it would not only improve patient care, but also save health care systems millions of dollars each year by reducing the number of treatments made necessary only because of bad care. In fact, such a financial incentive might be appealing to many countries now attempting to control their health care spending.

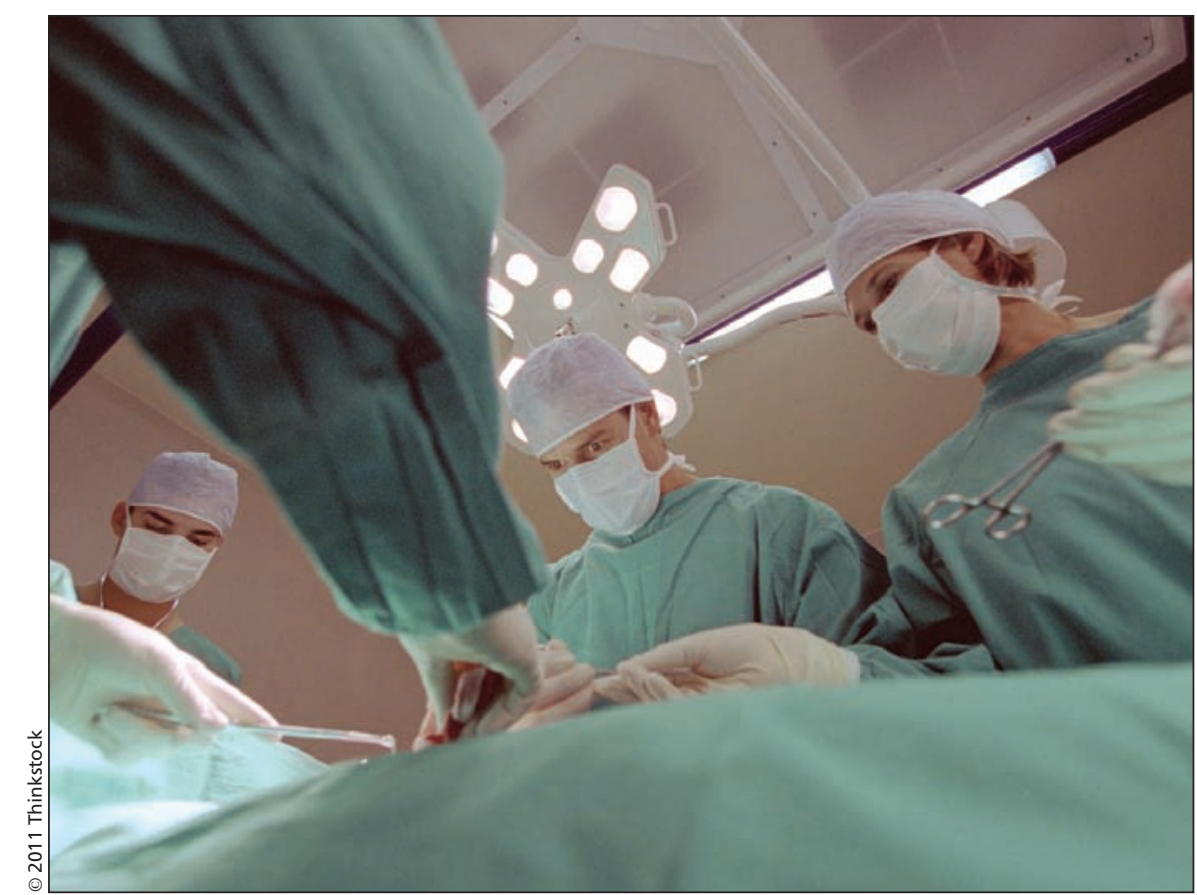

Eliminating or reducing additional hospital payments for treatments linked to preventable complications of surgery could be one step in implementing a pay-for-outcomes payment model.

would be to eliminate, or at least reduce, additional hospital payments for treatments linked to negative outcomes that could have been avoided, such as preventable complications of surgery. The United States appears to already be moving along that track within its Medicare program. In 2005, the coun-

\section{"You don't have to take a big bite to make an impact. On the other hand, it can't be one- hundredth of $1 \% . "$ - Dr. Norbert Goldfield}

"There would be no interest in this at all unless it was tied to money," says Dr. Norbert Goldfield, a contributor to the paper and medical director of clinical research for 3M Health Information Systems in Wallingford, Connecticut.

Of course, to see the financial rewards of a pay-for-outcomes health system, a jurisdiction must implement the payment model. A good first step try's Deficit Reduction Act mandated that Medicare eliminate payments associated with specific medical complications. Similarly, hospitals with high readmission rates will also receive less from Medicare under the Affordable Care Act of 2010.

The rewards or punishments in a pay-for-outcomes system must be substantial to actually induce change, Gold- field says. "You don't have to take a big bite to make an impact. On the other hand, it can't be one-hundredth of $1 \% . "$

But half of $1 \%$ could work. It did in Maryland. In 2009, under the Maryland Hospital Acquired Conditions Initiative, hospitals in the state stood to lose $0.5 \%$ of total inpatient revenue if they didn't collectively reduce rates of specified postadmission complications such as urinary tract infection. Within a year, preventable complications dropped by almost $12 \%$.

Other recommendations in Goldfield's paper for those jurisdictions that are considering a pay-for-outcomes payment system included: basing outcome standards on the outcomes of high-performing hospitals; tracking only outcomes and granting hospitals freedom to decide how to achieve those outcomes; linking penalties and rewards to a hospital's overall rate of negative outcomes rather than using a patient-specific approach; and adjusting risk for severity of illness and comorbid 
conditions so hospitals that treat more seriously ill patients aren't unfairly penalized for higher rates of negative outcomes.

Though the pay-for-outcomes payment model sounds good on paper, making it work in the health care system is another story, says Walter Wodchis, a professor of health care finance at the University of Toronto in Ontario. Linking negative outcomes to specific hospital procedures is difficult as there are many factors that affect how an individual reacts to a medical treatment: genetics, medical history, diet, fitness level and lifestyle, to name but a few.

"To all that variability we apply one single procedure and hope it works," says Wodchis.

The payment model would also be difficult to implement in hospitals with low patient volumes. In a small hospital, a few extra readmissions can have a big impact on the overall readmission rate, says Wodchis. "You really need to have sufficient volume to have stability in your results from year to year.".

Adjusting risk for severity of illness, an important part of making a pay-foroutcomes model work, is also tricky. There have been many attempts to create risk-adjustment models, notes Wodchis, and the results haven't been great. "It's right to say you need to try to implement risk adjustment. But that is hard to do." — Roger Collier, CMAJ

CMAJ 2011. DOI:10.1503/cmaj.109-3916 